Climatic Change, Volume 90, Numbers 1-2, pp 5-30, September 2008.

\title{
The concepts and development of a participatory regional integrated assessment tool
}

\author{
I.P. Holman ${ }^{1}$, M.D.A. Rounsevell ${ }^{2,8}$, G. Cojacaru ${ }^{3}$, S. Shackley ${ }^{4}$, C. McLachlan $^{4}$, \\ E. Audsley ${ }^{5,1}$, P.M. Berry ${ }^{6}$, C. Fontaine $^{2,8}$, P.A. Harrison ${ }^{6}$, C. Henriques ${ }^{1}$, M.
} Mokrech $^{7}$, R.J. Nicholls ${ }^{7}$, K.R. Pearn ${ }^{5,1}$ and J.A. Richards ${ }^{7}$.

${ }^{1}$ Natural Resources Department, Cranfield University, UK

${ }^{2}$ Université catholique de Louvain, Belgium

${ }^{3}$ Research Institute for Soil Science and Agrochemistry (ICPA), Bucharest

${ }^{4}$ Manchester School of Management, University of Manchester, UK

${ }^{5}$ Silsoe Research Institute, Wrest Park, Silsoe, Bedford, UK

${ }^{6}$ Environmental Change Institute, Oxford University Centre for the Environment, UK

${ }^{7}$ School of Civil Engineering and the Environment, University of Southampton, UK

${ }^{8}$ Now at School of Geosciences, University of Edinburgh, UK

Corresponding author: I.P. Holman

Cranfield University

Cranfield

Bedford MK43 0AL

United Kingdom

Tel: +44 (0) 1234750111 Ext. 2764

Fax: +44 (0) 1234752970

Email: i.holman@cranfield.ac.uk 


\begin{abstract}
This paper provides an overview of the development of the 'Regional Impact Simulator'- a user friendly software tool designed to allow stakeholders to perform integrated assessments of the effects of climate and/or socio-economic change on the important sectors and resources of two contrasting UK regions. This includes the assessment of agriculture, water resources, biodiversity and coastal and river flooding. The tool arose from the need to further develop the methods applied in the earlier RegIS project, which was the first local to regional integrated assessment in the UK. The limitations of RegIS, included very long run times, a limited number of simulations, incomplete linkages between models and no allowance for scenario uncertainty. Based upon the stakeholder needs identified within RegIS, a series of guiding principles were developed with Steering Committee stakeholders, which informed the concept of the 'Regional Impact Simulator' including functionality, appearance and complexity. An Integrated Assessment Methodology based upon the Drivers-Pressure-StateImpact-Response (DPSIR) framework facilitated the integration of multiple models, scenarios and datasets within the software interface. The development of the 'Regional Impact Simulator' provides a test-bed for further studies of stakeholder-led, regional, integrated assessment, and provides an opportunity to learn the many lessons in undertaking such studies.
\end{abstract}

\title{
1. Introduction
}

The impacts of predicted changes in climate (e.g. Hulme et al., 2002) due to human emissions of greenhouse gases (IPCC 2007) will be in addition to or concurrent with those associated with continuing socio-economic and political change (Nakicenovic and Swart, 2000). An holistic or integrated assessment of the effects of our changing future is therefore needed. Integrated assessment (IA) has been defined by the Intergovernmental Panel on Climate Change as "an interdisciplinary process that combines, interprets, and communicates 
knowledge from diverse scientific disciplines from the natural and social sciences to investigate and understand causal relationships within and between complicated systems" (IPCC, 2001).

It is fundamental to this definition that there are two main principles to integrated assessment: (1) integration over a range of relevant disciplines; and (2) the provision of new and appropriate information about how complex real-world systems might behave that enables or improves decision making (Harremoes and Turner, 2001; Jones, 2001; Yarnal, 1998). Department for Environment, Transport and the Regions - DETR (2000, p 138) assert that the regional (sub-national) scale studies are most relevant to decision-making, a view supported by Dessai and Hulme (2004) and Turnpenny et al., (2004). This is why the high level of spatial aggregation of many integrated assessment models and analyses (e.g. Dowlatabadi, 1995; Nordhaus and Yang, 1996; Alcamo et al., 1998; Parry et al., 1999; Tyson et al., 2001; Matsuoka et al., 2001; Toth, 2003) designed for climate policy at national or continental scales are inappropriate for many stakeholders who are operating at, or have responsibility for implementation of climate change adaptation policy at the local or regional level (Shackley and Deanwood 2002.

Within Europe, two of the potentially most far-reaching pieces of policy or legislation affecting landscape management are the Water Framework Directive (WFD) and the rural development reforms to the Common Agricultural Policy (CAP). Both are intended to deliver environmental, rather than economic, benefits and represent paradigm shifts in policy direction, from "end of pipe" to holistic solutions. This means river basin-based solutions to water quality problems under the WFD, whilst the CAP reform shifts the focus of agriculture away from solely food production to the delivery of additional services (e.g. environmental benefits, flood management etc). The importance of these policy changes and the relatively short period over which such paradigms shifts can occur demonstrates the real need for local to regional-based Integrated Assessments that address the environmental, rather than 
economic, impacts of change resulting not just from climate but also from socio-economic and policy change.

The application of downscaled socio-economic data to any scale of global change studies is only in the early stages (e.g. Arnell et al., 2004; Parry et al., 2004). As a result, few studies describe the results of regional (sub-national) scale assessments (e.g.; Rosenberg 1993, Yarnal, 1998; Yohe et al., 1999; Fisher, 2000; Strzepek et al., 2001; Carmichael et al., 2004; Holman et al., 2005 a \& b). Of these, RegIS (Holman et al., 2005 a \& b) was one of the few assessments to consider the effects of both socio-economic and policy change.

The 'Regional Climate Change Impact and Response Studies in East Anglia and North West England' (RegIS) study (Holman et al, 2005 a \& b) developed a stakeholder-led methodology for regional climate change impact assessment that explicitly evaluated local and regional (sub-national) scale impacts and adaptation options, and cross-sectoral interactions between four major sectors driving landscape change (agriculture, biodiversity, coasts / floodplains and water resources). At the end of the RegIS project, the UK Climate Impacts Programme (UKCIP) hosted a technical workshop for stakeholders to discuss the project results and to reflect on the lessons learnt. Key issues for future stakeholder-led Integrated Assessments came out of this workshop, as stakeholders wanted:

- simulations for more than two climate and two socio-economic scenarios and one future 30-year time-slice (the 2050s)

- Better understanding of the assumptions and effects of uncertainty within the climate and socio-economic scenarios;

- The ability to conduct sensitivity analysis to be able to better understand the effects of multiple interactions on impacts;

- More interactions between the drivers of change, the impacts, feedbacks and adaptive responses. 
It was axiomatic from these key issues that stakeholders desired to be able to perform their own integrated assessment- investigating the impacts and adaptive responses of relevance to themselves, rather than having to rely on the restricted outputs generated from a limited number of simulations chosen arbitrarily by researchers. However, stakeholder involvement is discouraged by the unacceptably long runtimes of most existing models (Wolfe et al., 2001). In an attempt to overcome these difficulties and make the RegIS methodology available to a wide stakeholder community of policy advisors, the two-year RegIS2 study (Holman and de Vries, 2005) was born- its aim being to develop the use of computationally simpler modelling techniques, so called 'metamodels' or 'reduced form models' (Carmichael et al., 2004), within a user friendly interface .

\section{Selection of the study areas}

It has been argued that for the results of a participatory IA to have relevance, the region being modelled must have some political relevance or influence (Carmichael et al 2004), but this places unequal weight on policy analysis at the expense of the public discussion purpose of participatory IA methods (Alcamo et al., 1996; van Asselt and Rijkens-Klomp 2002). However, while this approach recognises that (endogenous) regional processes may be influenced by (exogenous) global or supra-national factors, it fails to demonstrate the differing sensitivity and vulnerability of different regions to these factors.

The Regional Impact Simulator aims to improve the understanding of local/regional impacts of global change for a wide range of stakeholder audiences, and thereby to aid public discussion. In a climatically, physiographically and economically diverse country such as the United Kingdom, this was felt to be best supported by allowing the User to explore 
consequences in two contrasting regions (Table 1), rather than a single area. By capturing a significant range of the heterogeneity of the UK, it was intended that this would result in a generic methodology and also allow users to extrapolate their findings and understanding to other regions.

The North West is the larger of the two regions. It is dominated by higher land (up to about $900 \mathrm{~m}$ above sea level (masl)) in the north and along its eastern boundary; lower land is found in the west and south of the region. The proximity of the North Atlantic provides a moderating influence on climate, producing generally milder and wetter weather (average annual rainfall $=650-3200 \mathrm{~mm}$ ). The climate of East Anglia is influenced by its low relief (most land is below 60 masl) and its proximity to the continental land mass of Europe. It is less affected by the moderating influence of the sea, so rainfall (average annual rainfall $=550$ $-750 \mathrm{~mm}$ ) is lower and there is a greater daily and monthly temperature range than elsewhere in the UK.

\section{Methodological context}

RegIS (Holman et al., 2005a) demonstrated that the development of a robust, transparent and transportable methodology to assess regional climate change impacts across sectors is not a trivial task. Building upon stakeholder input within RegIS (described in Holman et al., 2005a) was fundamental to delivering a software interface (the 'Regional Impact Simulator') with simpler 'metamodels' to reach a wider stakeholder community. The inclusion and participation of stakeholders is vital in decisions that account for future change. Their specialised and practical knowledge is needed to evaluate adaptation options (Dessai and Hulme, 2004). To maximise the utility of the software interface, stakeholders gave their input on: 
- definitions of the components of the underpinning Integrated Assessment Methodology (IAM)

- design elements

- usefulness of output indicators for each of the metamodels;

- appropriateness of the regional adaptive responses;

- functionality of the interface

Underlying the advice and discussion regarding the development of the Regional Impact Simulator were the dilemma that a generic tool aimed at a wide range of stakeholder audiences should:

- raise awareness of the implications of policy decisions, but that it should not be used to 'test' specific detailed cases;

- familiarize people with the drivers, pressures, impacts and response options but that it cannot be detailed enough to meet the specific requirements and expectations of everyone;

- familiarize people with the assumptions and uncertainties involved in integrated assessments which prevent "prediction" or "interpretation" of the future;

- should be a tool for communicating and aiding public discussion but that it alone is no guarantee that people will agree or that their decisions are "best"; it cannot overcome the fact that individuals will interpret things differently, such as the drivers, pressures, impacts and response options to change.

These are discussed further in the proceeding sections

\subsection{RegIS2 Integrated Assessment Methodology}

The assessment framework was based on the Driver-Pressure-State-Impact-Response (or DPSIR) framework, which was first proposed by OECD (1993) and has been widely used in environmental management for the last 10 years, (e.g., Turner et al., 1998; La Jeunesse et al., 
2003; Holman et al., 2005a). It is a useful conceptual model for promoting dialogue between the different disciplines that must work together to solve complex environmental problems. It has been adopted by government agencies such as the England and Wales Environment Agency and the European Environment Agency (EEA, 2003).

There is also increasing demand for more integrated assessment of environmental change, which translates into a need to develop formal integrated assessment models. However, even when used in a conceptual role, important differences of opinion can arise as to what "driver", "pressure", etc mean and hinders more widespread application of the framework. When the DPSIR framework is used as the basis for models, the differences of interpretation have to be resolved and a consensus developed across the model developers and users, and ideally much more widely.

The agreed foci and methodological approaches of the DPSIR domains used in RegIS2 (Figure 1) for conducting an integrated climate change impact assessment are given below.

\section{Drivers:}

Definition: Causes of environmental change which are exogenous to the region, e.g. climate and socio-economic change, national and international (EU) policy.

Method: identify and describe qualitative, narrative storylines for several plausible future scenarios, e.g. based on the IPCC-SRES framework.

Examples:

- Coasts - Social change, economic change, climate change (sea level, storms, temperature);

- Agriculture- Social change (consumer preferences), climate change, economic change (supply \& demand), EU \& international policy change;

- Biodiversity - Climate change, environmental consciousness, concern for environmental sustainability, European nature conservation policy, recreation trends; 
- Water - Climate change, economic change (wealth, employment), environmental consciousness, concern for environmental sustainability, European water policy.

\section{Pressure:}

Definition: the variables that quantify drivers within the region, e.g. sea level, temperature, precipitation, regional population, regional GDP, crop prices or gross margins, standard of protection, per capita water demand, etc.

Method: develop regional, quantitative projections of pressure variables.

\section{Examples:}

- Coasts- Sea level, population, urbanisation, tourism, port and harbour development;

- Agriculture- Climate (temperature, precipitation, etc.), prices of goods, cost of production inputs (labour, fuel, chemicals etc.), subsidies, fossil fuel energy costs;

- Biodiversity- Climate, Number and size of protected sites, Land cover, Agrienvironment schemes, Local policy / management of protected sites;

- Water Climate, land cover, irrigation demand, domestic demand (household no., per capita usage), catchment abstraction management, industrial demand, leakage control; environmental flow objectives;

\section{State:}

Definition: variables that are representative of the system/sector and sensitive to pressure variables, e.g. extreme river flows and sea levels, land use areas, species distributions.

Method: use metamodels to derive sector-specific state variables that implicitly include autonomous (spontaneous) adaptation

\section{Examples:}

- Coasts- Coastal built environment (areas, totals), spatial distribution of coastal built environment (landscape quality), tourism arrivals (at coast), trade through ports and harbours (annual tonnage); 
- Agriculture- Crop yields, farm profit, crop areas, irrigation water demand, workable days, nitrate leaching, pesticides, area of biofuels;

- Biodiversity- Spatial distribution of species (presence/absence), Species and habitat vulnerability index, Biodiversity stewardship index (combining attributes of land use, land management and intent to maintain biodiversity);

- Water- River flows, recharge.

\section{Impact:}

Definition: a change in a state variable which has a negative or positive effect on individuals, society and/or environmental resources

Method: derive impact indicators which show whether the state variables reach a certain critical threshold, determined by expert knowledge/judgement, stakeholder views and historic analogues. Examples of impact indicators include the frequency of flooding, water supplydemand balance, species sensitivity index, etc.

\section{Examples:}

- Coasts- Loss of landscape quality, loss of accommodation space for wetland migration (coastal squeeze), average annual damages from erosion/flooding;

- Agriculture- Unacceptable farm profits, crop production below self-sufficiency level, irrigation water demand not achievable, land abandonment, water pollution, biofuel target;

- Biodiversity- Species or habitat vulnerability index increases; habitat degradation occurs when land use/management changes reach a critical level (represented by a change in the biodiversity stewardship index);

- Water- River flow below environmental flow objective, degree of water supplydemand imbalance.

\section{Response:}


Definition: planned (societal level) adaptation that aims to minimise negative impacts (or maximise positive impacts / benefits) by acting on the socio-economic pressure variables - a response may include several policy measures, e.g. changing water consumption, restricted housing development, water conservation plans, etc.

Methods: identify adaptation options with stakeholders; use the Regional Impact Simulator to evaluate ways of minimising impacts by modifying the socio-economic pressure variables.

\section{Examples:}

- Coasts- Spatial planning, improve flood defences, soft engineering for wetlands;

- Agriculture- Increase subsidies, promote rural diversification, extensification or intensification, encourage new crops, limit chemical inputs, on-farm reservoirs;

- Biodiversity- Expand protected areas, Agri-environment schemes to reduce stresses, habitat re-creation, managed retreat in coastal habitats;

- Water- Irrigation abstraction limits; water conservation (per capita demand), restrict new housing development.

The Drivers are in all cases qualitative descriptions of future environmental issues. They bound the problem that subsequent analyses will address at the regional scale. The pressures are the quantitative representation of these drivers that provide the inputs to the metamodels, although the pressures on one sector are sometimes derived from the states of another sector: land cover being a notable example. The states and impacts are the central outcomes of the metamodels. Finally, the responses then act on the pressure variables in ways that reflect, for example, alternative policy strategies. In using the Regional Impact Simulator, the user selects a 'scenario' that is based on a single 'storyline' and comprises multiple 'projections' (pressure variables).

It is important to note that there is no feedback of the responses to the drivers, i.e. climate mitigation policy is not considered to be an option at the scale of the study regions, or to the 
physical pressure variables (e.g. climate variables and sea level). Furthermore, the responses given are based on generic regional options, rather than as detailed specifications of how these responses could be implemented in practice. This recognises that the specialist knowledge of the stakeholders is an essential participatory component in using the Regional Impact Simulator, for downscaling generic adaptation options to practical actions or implementation strategies, which allow for technological, institutional, commercial or legislative constraints. Moreover, specific policy measures often reflect the institutional and political decision frameworks that exist at a given moment in time. Thus, alternative policy measures may arise from different decision frameworks, but the consequences of these policies in terms of environmental outcomes may be similar. The aim of the 'Regional Impact Simulator' therefore was to focus on the overall policy goals rather than specific policy measures.

\section{2 'Regional Impact Simulator' design}

The final version of the Regional Impact Simulator is freely available for download from the UKCIP website (www.ukcip.org.uk). This section describes the process of progressing from an initial design concept to the final software

\subsubsection{Initial concepts}

A highly intuitive interface should enable an interested individual to use the Regional Impact Simulator with minimal recourse to help files and, importantly, without need for training. A participatory approach (van Asselt and Rijkens-Klomp 2002) in designing the interface would therefore be crucial to the success of the project. Stakeholders, who formed the project's Steering Committee, would help. These individuals represented key groups including national and regional Government, non-government organizations and industry. The Steering Committee agreed: 
- The layout should be informed by the DPSIR components i.e. the user should be able to vary certain input parameters (Pressures) to look at the consequences (Impacts) and assess the need for changes (Response);

- Numerically-labelled, rather than qualitative descriptors of magnitude, slider bars should be used to display and vary input parameters and increase the transparency of the model/scenario assumptions (Schneider, 1997);

- Guidance must be given to estimate 'realistic' ranges of values within scenarios and to account for uncertainty (Turnpenny et al., 2004);

- The user should be able to concurrently view and compare output from more than one metamodel;

- The user should be able to explore topics in varying degrees of depth or detail

- $\quad$ Speed

- The user should not need to go through an extensive or prolonged model setup;

- The run times should be as short as possible to prevent Users 'switching off';

- Scale

- The principle outputs should be presented at regional scales;

○ More detailed mapped output should be available, but conditionally;

- Because the tool is not intended for intervention in specific policy analysis, the responses available should be given as regional outcomes rather than the policies that would accomplish those outcomes.

Based upon the initial underlying concepts for the Regional Impact Simulator, the first 'mock-up' design agreed with the stakeholder Steering Committee is shown in Figure 2.

\subsubsection{Final design}


The RegIS2 study confirmed earlier studies that significant effort is required to create a clear user interface (Turnpenny et al., 2004). Hence the Regional Impact Simulator went through many subsequent iterations with input from the project team and Steering Committee over a period of two years. Important additions or evolutions to the initial design include:

- The original single screen interface evolved to three screens each with a different purpose, and increasing levels of interaction with the model variables. The single interface screen became too complex and off-putting to some stakeholders. The screens now provide an ordered hierarchy of user interaction with the simulator and, more importantly, the DPSIR approach to thinking about change:

○ The Predefined Scenario Futures screen (Figure 3) allows the user to rapidly become familiar with indicators and their sensitivity to the different climate and socio-economic scenarios. The default set of values for each scenario is based upon pre-existing data (e.g. from Hulme et al., 2002 or Shackley and Deanwood, 2003) or expert judgement.

- The Exploratory Analysis screen (Figure 4) allows the user to explore a scenario in greater detail by changing the scenario pressure variables (input parameter values) used in the models. This enables the user to explore the effects of the widely acknowledged uncertainty in any scenario, which cannot be defined by a single set of unique values.

$\circ$ The Influencing the Impacts screen (Figure 5) allows the user to test regional adaptation responses to the impacts identified with the Exploratory Analysis screen. After an impact indicator is selected, a list of responses which are known to affect the chosen indicator is presented. The user is able to "respond" to the impact by changing sliders which thus change the parameters and re-running the model. Changes in the model outputs allow the user to identify potential regional adaptation responses that reduce or minimise the impact. 
- Extensive use of tooltips were included to minimize the user from having to resort to the Help Files; by hovering the mouse over a component or term on the screen a short definition or explanation appears

- A traffic light-based system of colour coding of the slider bars was used to communicate the uncertainty of a scenario; green denotes uncertainty that is "credible" within the context of a scenario storyline (green for 'go'); yellow denotes wider uncertainty that may be possible, but which is outside of the considered wisdom for the scenario (yellow for 'caution'). For obvious reasons, a user is not permitted to enter a red, or 'no go' zone;

- A library of photographs of plant species was included;

- Climate mitigation is a "response" that has an effect on climate "pressures" in the model e.g. rainfall. However, a regional scale mitigation response, in isolation, will not affect the future climate. Therefore, it was decided to separate the Pressures (which include the climate variables) from the Responses within the Interface, by the creation of the separate 'Influencing the Impacts' screen to explore adaptation.

\subsection{Modular integration within the 'Regional Impact Simulator'}

According to Leimbach and Jaeger (2004), the typical IA model is a "more or less monolithic model, in which different components, programmed in the same programming language, are strongly interlinked with each other". They can range from models with relatively compact coding (e.g. the DICE model- Nordhaus, 1994) to detailed mechanistic models with complex coding (e.g. the IMAGE model- Alcamo, 1994).

However, the simulator relies on diverse software programs. The development of each metamodel was undertaken by sectoral specialists working within different institutions that were not computer scientists and who used different model development paradigms and 
programming languages. To facilitate metamodel development, calibration and validation at the different universities and research institutes within RegIS2, a modular approach to model integration was adopted. An Object Oriented approach allowed the modules (or metamodels) which were written in various programming languages to be compiled in libraries of executable functions (DLLs) or executables (EXEs). The meta-models are run as serial processes (sequentially in the order: High River Flow, Flood, Agriculture, Water Resources, Biodiversity) with the inclusion of parallel processes where possible.

The modular architecture means that all of the metamodels can be run autonomously. They are developed and tested as stand-alone versions before being integrated with the other metamodels and interface components. The modular architecture allows the metamodels to be replaced or updated as required without disabling the entire simulator (provided that their output data files meet the agreed format and structure of data exchange). This greatly aids model development. It does not, however, eliminate the need for calibration, validation and testing because many of the metamodel inputs depend on the outputs of other metamodels.

The need to achieve agreement about the format and types of information exchange is of primary importance in developing a successful tool. Although desirable, it is rarely possible to define this from the outset. Therefore flexibility is required to accommodate new and evolving requests from the model developers and users.

\section{Scenarios}

\subsection{Climate scenarios}

Four climate change scenarios for 30 year-timeslices were included in the simulator - 2020s Low emissions, 2020s High emissions, 2050s Low emissions and 2050s High emissions - 
from the UKCIP02 scenarios (Hulme et al., 2002). The Low and High emissions scenarios capture the effects of uncertainties in future global greenhouse gas emissions on UK climate, while the two timeslices (2020s and 2050s) allow investigation of the evolution of change. Increases in mean annual temperature, relative to $1961-90$, range from 0.3 to $1.1^{\circ} \mathrm{C}$ for the $2020 \mathrm{~s}$ and 0.5 to $2.6^{\circ} \mathrm{C}$ for the $2050 \mathrm{~s}$. In all seasons, and for all scenarios, there is a northwest to southeast gradient in the magnitude of the climate warming over the UK, the southeast consistently warming by several tenths of a degree Celsius more than the northwest. Changes in total annual precipitation, relative to $1961-90$, range from -4 to $+3 \%$ by the 2020 s and -9 to $+7 \%$ by the $2050 \mathrm{~s}$. Winter precipitation increases in all regions with the largest changes of up to $23 \%$ occurring in the east. Conversely, in summer, precipitation decreases across virtually all of the UK with the largest changes of up to $-32 \%$ occurring in the south. Globalaverage sea levels are predicted to rise by $6-7 \mathrm{~cm}$ by the $2020 \mathrm{~s}$ and $14-18 \mathrm{~cm}$ by the $2050 \mathrm{~s}$.

All of the UKCIP02 scenarios are based on the high-resolution regional climate model (HadRM3) from the Hadley Centre for Climate Prediction and Research, but the credible uncertainty range on the climate pressure slider bars indicates the range of predictions of regional climates over the UK simulated by other global climate models based on Hulme et al., (2002).

\subsection{Socio-economic scenarios}

Future socio-economic change can be as significant, if not more significant, than climate change for some sectors (Holman et al., 2005b; Rounsevell et al., 2005; Rounsevell et al., 2006), such that the widespread practice of studying the impacts of future climate change as if it were to affect today's society is becoming increasingly untenable. Socio-economic scenarios are, to a certain extent, based on assumptions that are known to be tenuous (Gaffin et al., 2004). However, such scenarios are not intended to predict the future, but help to 
evaluate societal responses to major environmental changes such as global climate change, assuming that (Morris et al., 2004):

1. The future is unlike the past, and is shaped by human choice and action;

2. The future cannot be foreseen, but exploring the future can inform present decisions;

3. There are many possible futures, so scenarios map the 'possibility space';

4. Scenario development involves a mix of rational analysis and subjective judgement.

In accordance with the RegIS funders and UKCIP, socio-economic scenarios (also referred to as 'non-climate change' scenarios) were used. In contrast to co-evolutionary scenarios (e.g. Lorenzoni et al., 2000) where climate and socio-economic changes interact, these scenarios look at socio-economic change in isolation (without the compounding effects of climate change). Using 'non-climate change' socio-economic scenarios has the benefit that it permits a clearer distinction between the effects of physical climate change, and socio-economic changes (and hence identifies more clearly the role of response to the impacts identified), which are difficult to untangle within co-evolutionary socio-economic scenarios.

The four original RegIS socio-economic scenarios for the two regions (Holman et al., 2005a; Shackley \& Deanwood, 2003) were refined, updated and an improved spatial resolution implemented. From the qualitative scenarios for the region, projections for a number of quantitative non-spatial and spatial indicators have been developed for use as inputs to the numerical models, based on the qualitative storylines and informed by regional trends, Government projections and Regional Planning Guidance. These indicators are: population, Gross Value Added (GVA), persons per household, population density and spatial distribution of development, woodland and Protected Areas (e.g. National Parks, designated sites, nature reserves etc).

The regional descriptive storylines of alternative futures were derived from an iterative procedure between researchers and stakeholders at national, regional and local levels and are 
broadly similar to the related national (UKCIP, 2001; Berkhout et al., 2002) and global narratives (Nakicenovic and Swart, 2000; Arnell et al., 2004). The four regional scenarios are

- Global Sustainability: the global approaches to achieving sustainable development take precedence over regional responses. The World is seen as an interconnected whole, functionally and morally, with a concentration on the wider impacts of individual actions.

- Global Markets: based on the pursuit of high and sustained growth within a global context. All regional assets will be brought to bear in this ambition and significant risks will be taken as to the precise composition of the development path.

- Regional Stewardship: an emphasis on recognising and conserving regional assets, accepting that this might result in a significantly reduced level of economic growth and even a contraction of the economy in some respects. This is accepted because of the pursuit of a more all-embracing means of living, one which recognises the importance of community and the value of local natural assets.

- Regional Enterprise: the most bullish of the scenarios, suggesting vibrant, semiautonomous regions, keen to promote and maintain their distinctive qualities in a highly competitive world. A key to their success will be the imaginative development of assets and core strengths, some economic, some social, others environmental.

\subsection{Scenario linkage -how to link and what to link}

Only one option to date links the formally independent climate and socio-economic (nonclimate) scenarios: internally consistent emissions scenarios. This is based on the rationale that certain socio-economic scenarios (i.e.; a strong market-driven socio-economic scenario such as Global Markets) will likely be consistent with higher emissions of carbon, whilst 
others (i.e.; a community-based socio-economic scenario such as Regional Stewardship) will be more consistent with lower emissions of carbon.

The alternative and chosen approach within the simulator was to provide no formal linkage between the two sets of scenarios, but to leave the choice to the user. This approach was preferred because of the greater flexibility afforded to the user (Table 2). The climate change scenarios are dependent upon global emissions of carbon; the socio-economic scenarios operate at a range of scales from the local to global. Formally linking the socio-economic scenarios and the climate change scenarios - within this simulator - would mean choosing one socio-economic scenario that would prevail at local as well as regional and national levels and hold true everywhere in the world. This is a highly unlikely situation. So the ability to investigate alternative trajectories of regional socio-economic development (e.g. Turnpenny et al., 2005 and CRed - Carbon Reduction Programme in the East of England) that are not necessarily consistent with global developments was allowed.

\section{Metamodels}

The environmental and resources sectors modelled (agriculture, biodiversity, coasts and floodplains and water resource management) were originally selected as a result of stakeholder concerns in the study areas (Science and Policy Associates \& ESYS, 1996). However, the scope of the models, their output indicators and the linkages between the models have been greatly expanded and improved from their initial form in RegIS (described in Holman et al., 2005a). 


\subsection{Flooding (fluvial and coastal environments)}

The flooding metamodel (Mokrech et al., 2008) considers the impacts of both climate changeinduced sea-level rise and changing flood flows in rivers, and the effects on the distribution of saltmarsh and coastal and fluvial grazing marsh. The flooding methodology uses the 2003 Indicative Floodplain Map (from the Environment Agency) to identify the flood hazard zones for the 200-year and 100-year events for coastal and fluvial floodplains, respectively. The effect of relative sea level rise on coastal flooding is estimated by raising the present surge heights by the magnitude of relative sea-level rise (i.e. including regional land uplift/subsidence), leading to a reduction in the defence standards (Nicholls and Wilson, 2001). For fluvial flooding, the High Flows metamodel, based on the Catchment Descriptors method (Bayliss, 1999), simulates the median annual flood (or $\mathrm{Q}_{\mathrm{MED}}$ ) Indicator (Robson and Reed, 1999). An increase in this peak river flow is translated into an increase in the risk of flooding and vice versa. This is based on a relationship between the change in flow, initial standard of protection afforded by flood defences and change in defence standard.

The impact of sea level rise on coastal habitats (Richards et al., 2008) is modelled based on the capacity for saltmarshes to respond vertically (accrete) and horizontally (retreat / advance) to sea-level rise. The user can explore the potential for saltmarsh gains to occur, for example, due to managed realignment of coastal defences (a response) or unplanned coastal abandonment (another response option), but will often be at the expense of coastal grazing marsh (another impact) (Nicholls and Wilson, 2001). The creation of compensatory inland fluvial grazing marsh in sustainable locations is also explored by the metamodel.

\subsection{Agriculture}

The agriculture metamodel (Audsley et al., 2008) was developed to simulate rapidly the results of the agricultural land use model described in Holman et al., (2005a) and Rounsevell 
et al., (2003). The method combines a metamodel that estimates the yield of a wide range of crops as a function of climate and soil type with a farm metamodel which determines the optimum cropping given crop gross margins, labour and machinery costs and soil workability (see Rounsevell et al., 2003, for a full explanation). The yield metamodel used a neural network fitted to spatial modelled yield data (from Holman et al., 2005a), derived using the ACCESS model and data on soil, weather, latitude, carbon dioxide and irrigation.

Based upon the input variables set by the user, the farm metamodel calculates the area of each crop that maximises profit according to the crop gross margin of the crop, the soil type and workable hours in the winter, the maturity date of each crop, spring and autumn evaporation and rainfall, and the change in labour and machinery costs. A regression approach is used to predict the percentage of the farm in a given crop and the profit. The results of the agricultural metamodel then give the level and area of production of each commodity in each region.

\subsection{Water resources management}

The water resources management metamodel (Henriques et al., 2008) has a number of modules operating at different spatial scales. For each catchment, the naturalized flow duration curve (FDC) is simulated based upon the Low Flow Estimation methodology (Gustard et al., 1992) according to the distribution of soil types, urbanization (from the socioeconomic scenarios), climate, cropping and land use classes (from the Agricultural metamodel). From the FDC, the availability of water for abstraction in each catchment is calculated, after allowing for the environmental flow requirements of the river (Dunbar et al., 2004). This limits abstraction to protect low flows and flow variability, whilst also recognising that abstraction is not unlimited at the high flow end of the FDC. 
A region includes many catchments. The regional water supply availability is derived from the abstraction availability in its catchments, water imports/exports and reservoir storage. Regional water demand is calculated from the agricultural water demand (output from the agricultural metamodel), domestic, industrial and commercial demand (based upon the socioeconomic scenario selected) and leakage from the mains water network. Finally a supplydemand balance for the region provides a measure of the robustness of the supply-demand system to the pressures exerted in the scenario, and hence the need (or not) for adaptation.

\subsection{Biodiversity}

The SPECIES model (Spatial Estimator of the Climate Impacts on the Envelope of Species; Pearson et al., 2002; Harrison et al., in press) is used to simulate the impacts of climate change on the potential geographical distribution of 46 species associated with 8 habitats that interact with the agricultural, coastal and water environments. SPECIES uses an artificial neural network to characterise the currently suitable climate space for a species and to estimate likely changes in its spatial distribution. In this way it is possible to examine how the climate space of individual species contracts, expands or shifts as the climate changes.

Predictions of potential climate space for each species are combined with data on the distribution of habitats, protected sites and outputs from the other metamodels to simulate the impacts of climate and socio-economic changes on species' suitability at the regional scale (Harrison et al., 2008). For the coastal species, simulated changes in salt marsh and coastal and floodplain grazing marsh areas are used. For fens and bog species, outputs from the water resources metamodel of indicators of low and high flows are related to species' preferences for dry and wet conditions, respectively. For lowland heath and upland hay meadows, output from the agricultural metamodel for land use distribution and from the socio-economic scenarios of the distribution of protected sites is used to assess habitat loss. Habitat re-creation is simulated according to rules associated with historic habitat 
distributions, relevant soil properties, output from the agricultural metamodel on land use distribution and proximity to existing habitat. Finally, for cereal field margins, outputs from the agricultural metamodel on nitrogen inputs and the distribution of arable land use are related to species' tolerances to nitrogen stress for plants, whilst output on switches from spring to autumn sowing is related to the availability of over-winter food supplies for higher organisms.

Figure 6 demonstrates how the metamodels interact.

\section{System performance}

The run times for the Regional Impact Simulator are longer than was initially hoped for, prior to model development. This partly relates to the finer spatial resolution adopted by the flooding metamodel $(1 \mathrm{~km})$ and partly to the reading and writing of files between the metamodels. The runtime is also highly computer-dependent, as can be seen from Table 3 , which shows the run-times for three contrasting PCs. Although the new PC had a run time of less than 20 seconds, this can be reduced to around 10 seconds when run without the biodiversity models- the last in the cascade of metamodels.

\section{Discussion}

There is a need for tools such as the Regional Impact Simulator. But stakeholder-led software design and the integration of the simulator components are difficult.

Within the UK, there is an acknowledged need for better quality, locally-relevant information on climate change impacts. The UK government (DETR, 2000) has identified the need for more detailed and quantitative impact assessments to underpin regional adaptation strategies. One reason cited for the rather limited response of local government to climate change is 
‘difficulty accessing and interpreting good-quality environmental information’ (RCEP, 2002 para 6.4).

Accessibility refers to both cognitive accessibility - the ease of understanding - and practical accessibility - the ease of application (Demeritt and Langdon, 2004). In their analysis of the reception and response of local government to climate change information, Demeritt and Langdon (2004) demonstrated the importance of credibility and its appropriateness to the audience. They also showed positive associations between the perceived accuracy of an information source (e.g. Government Department, internet, NGO's etc) and the frequency of use of information from that source, and between frequency of use and ease of understanding. This suggests that there is a need for tools such as the Regional Impact Simulator, but only if they are perceived by stakeholders as: credible, accurate, easy to understand, and appropriate.

The development of an easy to use and efficient software tool for a broad range of stakeholders involves compromises. For example, if speedier model runtimes are necessary then the model complexity must be reduced in their form. It is therefore important to judge whether an acceptable balance has been met by satisfying the above requirements in the Regional Impact Simulator.

\subsection{Does the Regional Impact Simulator provide credible outputs?}

Credibility reflects the ability of users to understand both the models' assumptions and the links between the model outputs and the choices they have made (Carmichael et al 2004). There are many elements to credibility including testable calculations, transparency (of models assumptions, cause-effect linkages etc), inclusion of critical issues (Alcamo et al., 1996) and for an acceptable balance between openness and rigour (Fontela, 2000). The multiple facets that underpin the credibility of an IAM in the eyes of stakeholders must be 
approached from a variety of perspectives. To increase the likelihood that stakeholders would find the Regional Impact Simulator credible, the following were done:

- The metamodels were based on widely accepted pre-existing models (e.g. SPECIESPearson et al., 2002; Flood Estimation Handbook - Bayliss, 1999; Low FlowsGustard et al., 1992; Silsoe Whole Farm Model- Rounsevell et al., 2003);

- The simplification of the pre-existing models into metamodels allows them to be understood and explained in lay terms (Turnpenny et al., 2004);

- The slider bars with which the user changes the Pressures or Responses show the numerical values, as opposed to qualitative descriptors (e.g. "less", "more" etc. as used in GB-QUEST-Carmichael et al., 2004) to make the magnitude of the changes being made by the user more clear;

- Fast runtimes enable users to carry out many simulations and rapidly investigate the sensitivity of the system under baseline conditions to changes to the Pressure variables, and to compare this, where appropriate, with their own knowledge;

- When an Indicator of concern is selected in the Influencing the Impacts screen, the user is automatically guided to the Responses that affect that Indicator making more transparent those choices with greatest potential effect;

- A hierarchy of user support was implemented: tooltips give immediate short definitions and explanations of interface features; help files give background information about a scenario / model / indicator etc, sufficient for the vast number of users; and full documentation is also provided within the Help files for the technical users who require it;

- Explicitly communicating that the model inputs themselves, which are derived from the scenarios, are uncertain. A major challenge in modelling is how to convey uncertainty in understandable and approachable ways (Carmichael et al., 2004). Considerable effort has been expended on methods of conveying uncertainty (e.g. Kandlikar et al., 2005). The colour coding approach used in the Regional Impact 
Simulator, and the breadth of these traffic light-coloured uncertainty bands on the slider bars conveys clearly that different, but plausible, values (due to the uncertain assumptions behind them) are likely to give rise to differing outcomes - which the user is encouraged to explore.

\subsection{Can the outputs of the simulator be demonstrated to be accurate?}

As described in Mokrech et al. (2008), Henriques et al. (2008), Audsley et al. (2008), Harrison et al. (2008) and Richards et al. (2008), all of the reduced form models within the simulator have either been validated against model results from peer-reviewed, pre-existing models or against observed data. Their accuracy can therefore be demonstrated.

Approaching stakeholders with these reports and academic papers, however, is unlikely to be effective. Relevant information needs to be easily accessible at the time the user is actually engaged in an assessment activity, which in a tool such as the Regional Impact Simulator is achieved by clearly incorporating the information within the Help File of the software.

\subsection{Are the results easy to understand?}

The intuitiveness of the Interface and the usefulness of the indicators and results were all generally positively received in the evaluation (described in Holman and Harman, 2008), suggesting that this modelling system is relatively easy to understand for a wide range of stakeholders.

\subsection{Are the results appropriate to the target audience?}

The Regional Impact Simulator is a generic tool intended to interest a wide range of practitioners, who have different interests, operating under a variety of different conditions and constraints. Recognizing that a generic tool cannot be all things to all people, the 
evaluation of its usefulness was generally positive. More specific applications that link to specific plans, policies or strategies would require customized versions (Demeritt and Langdon 2004) as there are too many possibilities. More specific application therefore depends on the expert judgement of the users to re-interpret the results in light of their own knowledge of their field. To be successful, the user needs to take the time to explore and think.

Despites its general nature, comments received during the evaluation of the Regional Impact Simulator (described in Holman and Harman, 2008) suggest that a range of stakeholders recognise the potential for the outputs to support their activities.

"We believe that [the Regional Impacts Simulator] has a huge potential to raise awareness of the implications of policy decisions, and therefore guide policy and decision makers down a more sustainable track"

"It's very encouraging to see the potential solutions for many items that are put into the 'too difficult' box."

"tool provides a valuable (essential) advocative medium to embed need for adaptation and underpin cross sectoral policy development/decision making"

\section{Conclusions}

This article describes the application of a participatory design approach to the development of a regional integrated assessment tool, the Regional Impact Simulator. The Regional Impact Simulator was designed to allow a wide range of stakeholders to explore potential climate and socio-economic change in two regions of England and the potential future consequences of their responses. The development of a highly intuitive interface requires a participatory approach to design. Early stakeholder engagement provided agreed fundamental design and 
functionality concepts at the outset. However, participatory design requires an iterative approach to both software and interface development, which is not best served by conventional programming. The object-oriented approach used in the Regional Impact Simulator has demonstrated the value of software modularity in allowing different research groups to iteratively develop their models autonomously according to progressive stakeholder feedback. The ultimate credibility of any Integrated Assessment tool in the eyes of stakeholders is not a given. A multifaceted approach was adopted, encompassing transparency, interactivity, hierarchical user support and explicit communication of uncertainty. The use of metamodels or reduced form models, together with binary file exchange, has enabled the Regional Impact Simulator to provide the stakeholder User with interactive integrated assessments of the effects of climate and/or socio-economic change on agriculture, water resources, biodiversity and coastal and river flooding in typically less than 20 seconds. However, the responses given by the Simulator are based on generic regional options, rather than as detailed specifications of how these responses could be implemented in practice. This recognises that the specialist knowledge of the stakeholders is an essential participatory component in using the Regional Impact Simulator. It is hoped that the provision of such tools for use by stakeholders will help them better prepare for the impacts of climate change.

\section{Acknowledgements}

The Regional Impact Simulator was developed as part of the RegIS2 project (project CC0362), which was funded by the Department for Environment, Food and Rural Affairs within the UK Climate Impacts Programme (UKCIP), with support from UK Water Industry Research (UKWIR). The advice and guidance of the Steering Committee members from UKWIR, English Nature, Environment Agency, Government Office for the East Of England, South East Climate Change Partnership, UKCIP and Defra has provided invaluable assistance. We thank Rachael Dempsey for her constructive reviewer comments. 


\section{References}

Alcamo J (1994) IMAGE 2.0 - Integrated Modelling of Global Climate Change. Kluwer, Dordrecht

Alcamo J, Kreileman GJJ, Leemans R (1996) Global models meet global policy. Global Environmental Change 6(4): 255-259

Alcamo J, Leemans R, Kreileman E (eds) (1998) Global Change Scenarios of the 21st Century: Results from the IMAGE 2.1 Model. Elsevier, Oxford

Arnell NW, Livermore MJL, Kovats S, Levy P, Nicholls R, Parry ML, Gaffin SR (2004) Climate and socio-economic scenarios for global-scale climate change impacts assessments: characterising the SRES storylines. Global Environmental Change 14(1): $3-20$

Audsley E, Pearn KR, Harrison PA and Berry PM (2008) The impact of future socioeconomic and climate changes on agricultural land use and the wider environment in East Anglia and North West England using a metamodel system. Climatic Change 90(1-2), 57-88

Bayliss A (1999) Flood Estimation Handbook Volume 5: Catchment descriptors. Institute of Hydrology, Wallingford

Berkhout F, Hertin J, Jordan A (2002) Socio-economic futures in climate change impacts assessment: using scenarios as learning machines. Global Environmental Change 12: 83-95

Carmichael J, Tansey J, Robinson J (2004) An integrated assessment modelling tool. Global Environmental Change 14: 171-183 
Demeritt D, Landgon D (2004) The UK Climate Change Programme and communication with local authorities. Global Environmental Change 14: 325-336

Dessai S, Hulme M (2004) Does climate adaptation policy need probabilities. Climate Policy 4: 107-128.

DETR (Department for Environment, Transport and the Regions) (2000) Climate change : the UK Programme. HMSO, London

Dowlatabadi H (1995) Integrated assessment models of climate change: An incomplete overview. Energy Policy 23(4/5): 289-296

Dunbar MJ, Acreman MC, Kirk S (2004) Environmental flow setting in England and Wales - current practice: future challenges. J. Water Environ. Manage 18: 5-10

EEA [European Environment Agency] (2003) Europe's environment: the third assessment. Environment Assessment Report No. 10, European Environment Agency, Copenhagen

Fisher A (2000) Preliminary findings from the Mid-Atlantic Regional Assessment. Climatic Research 14(3): 261-269

Fontela E (2000) Bridging the gap between scenarios and models. Foresight: the Journal of Future Studies 2(1): 11-14

Gaffin SR, Rosenzweig C, Xing X, Yetman G (2004) Downscaling and geo-spatial gridding of socio-economic projections from the IPCC Special Report n Emissions Scenarios (SRES). Global Environmental Change 14: 105-123

Gustard A, Bullock A, Dixon JM (1992) Report No. 108 Low flow estimation in the United Kingdom. Institute of Hydrology, Wallingford

Harremoes P, Turner RK (2001) Methods for integrated assessment. Regional Environment Change 2: 57-65 
Harrison PA, Berry PM, Butt N, New M (in press) Modelling climate change impacts on species' distributions at the European scale: Implications for conservation policy. Environmental Science and Policy

Harrison PA, Berry PM, Henriques C and Holman IP (2008) Impacts of socio-economic and climate change scenarios on wetlands: linking water resource and biodiversity metamodels. Climatic Change 90(1-2), 113-139

Henriques C, Holman IP, Audsley E and Pearn K (2008) An interactive multi-scale integrated assessment of future regional water availability for agricultural irrigation in East Anglia and North West England. Climatic Change 90(1-2), 89-111

Holman IP and Harman J (2008) Preliminary evaluation of the benefits of a participatory regional integrated assessment software. Climatic Change90(1-2), 169-187

Holman IP, de Vries TT (eds.) (2005) 'Development of a metamodel tool for regional integrated climate change management (RegIS2)'. Final Report for Project No. CC0362, Department for Environment, Food and Rural Affairs, London

Holman IP, Rounsevell MDA, Shackley S, Harrison PA, Nicholls RJ, Berry PM, Audsley E (2005a) A regional, multi-sectoral and integrated assessment of the impacts of climate and socio-economic change in the UK: I Methodology. Climatic Change 71: 9-41

Holman IP, Nicholls RJ, Berry PM, Harrison PA, Audsley E, Shackley S, Rounsevell MDA (2005b) A regional, multi-sectoral and integrated assessment of the impacts of climate and socio-economic change in the UK: II Results. Climatic Change 71: 43-73

Hulme M, Jenkins GJ, Lu X, Turnpenny JR, Mitchell TD, Jones RG, Lowe J, Murphy JM, Hassell D, Boorman P, McDonald R, Hill S (2002) Climate Change Scenarios for the United Kingdom: The UKCIP02 Scientific Report. Tyndall Centre for Climate Change Research, School of Environmental Sciences, University of East Anglia, Norwich 
IPCC (2007) Climate Change 2007: The Physical Science Basis. Contribution of Working Group I to the Fourth Assessment Report of the Intergovernment Panel on Climate Change. Cambridge University Press, New York, pp996

IPCC (2001) Technical Summary. Climate change 2001: Impacts, Adaptation, and Vulnerability. A Report of Working Group II of Intergovernmental Panel on Climate Change Cambridge University Press, New York

Jones RN (2001) An environmental risk assessment/management framework for climate change impact assessments. Natural Hazards 23(2-3): 197-230

Kandlikar M, Risbey J, Dessai S (2005) Representing and communicating deep uncertainty in climate-change assessments. External Geophysics, Climate and Environment 337: 443-455

La Jeunesse IM, Rounsevell MDA, Vanclooster M, Romanowicz AA (2003) Delivering a Decision Support System tool to a river contract : a way to implement the participatory approach principle at the catchment scale? Physics and Chemistry of the Earth 28: 547554

Leimbach M, Jaeger C (2004) A modular approach to Integrated Assessment modelling. Environmental Modelling and Assessment 9: 207-220

Lorenzoni I, Jordan A, Hulme M, Turner RK, O'Riordan T (2000) A co-evolutionary approach to climate change impact assessment: Part I. Integrating socio-economic and climate change scenarios. Global Environmental Change 10: 57-68

Matsuoka Y, Morita T, Kainuma M (2001) Integrated Assessment Model of Climate Change: The AIM Approach. In: Matsuno T, Kida H (eds) Present and Future of Modelling Global Environmental Change: Toward Integrated Modeling. Terra Scientific Publishing Company, Tokyo 
Mokrech M, Nicholls RJ, Richards JA, Henriques C, Holman IP and Shackley S (2008) Regional impact assessment of flooding under future climate and socio-economic scenarios for East Anglia and North West England. Climatic Change 90(1-2), 31-55

Morris J, Gomez M, Vasileiou K, Berbel J (2004) WADI scenario definition. In: Vecino JB, Martin CG (eds) Sustainability of European Irrigated Agriculture under Water Framework Directive and Agenda 2000. Final report of $5^{\text {th }}$ Framework project EVK12000-00057, ISBN 92-894-8005-X.

Nakicenovic N, Swart R (eds) (2000) Special Report on Emissions Scenarios. A Special report of Working Group III of the Intergovernmental Panel on Climate Change. Intergovernmental Panel on Climate Change, Cambridge University Press, Cambridge

Nicholls RJ, Wilson T (2001) Chapter five. Integrated impacts on coastal areas and revir flooding. In Holman IP, Loveland PJ (Eds.) Regional Climate Change Impact and Response Studies in East Anglia and North West England (RegIS). Final Report of MAFF project no. CC0337. (downloadable at www.ukcip.org.uk).

Nordhaus WD (1994) Managing the Global Commons. MIT Press, Cambridge

Nordhaus WD, Yang Z (1996) RICE: a Regional Dynamic General Equilibrium Model of Alternative Climate Change Strategies. Amer. Econ. Rev. 86: 726-741

Organization of Economic Co-operation and Development (1993) OECD Core set of indicators for environmental performance review. Environmental Monograph No. 83, OECD, Paris

Parry M, Arnell N, Hulme M, Martens P, Nicholls R, White A (1999) The global impact of climate change: a new assessment. Global Environmental Change 9: S1-S2

Parry M, Rosenzweig C, Iglesias A, Livermore M, Fischer G (2004) Assessing the effects of climate change on global food production under different socio-economic scenarios. Global Environmental Change 14(1): 53-67 
Pearson RG, Dawson TP, Berry PM, Harrison PA (2002) SPECIES: A spatial valuation of climate impact on the envelope of species. Ecological Modelling 154(3): 289-300.

RCEP (Royal Commission for Environmenal Pollution) (2002) Environmental Planning. [available at http://www.rcep.org.uk/epreport.htm]

Richards JA, Mokrech M, Berry PM and Nicholls RJ (2008) Regional assessment of climate change impacts on coastal and fluvial ecosystems and the scope for adaptation. Climatic Change 90(1-2), 141-167

Robson A, Reed D (1999) Flood Estimation Handbook Volume 3: Statistical procedures for flood frequency estimation. Institute of Hydrology, Wallingford

Rosenberg NJ (1993) A methodology called 'MINK' for study of Climate Change Impacts and responses on the Regional Scale. Climatic Change 24: 1-2, 1-6

Rounsevell MDA, Annetts JE, Audsley E, Mayr T, Reginster I (2003) Modelling the spatial distribution of agricultural land use at the regional scale. Agriculture, Ecosystems and Environment 95(2-3): 465-479

Rounsevell MDA, Ewert F, Reginster I, Leemans R, Carter TR (2005) Future scenarios of European agricultural land use. II: projecting changes in cropland and grassland. Agriculture, Ecosystems and Environment 107: 117-13

Rounsevell MDA, Reginster I, Araújo MB, Carter TR, Dendoncker N, Ewert F, House JI, Kankaanpää S, Leemans R, Metzger MJ, Schmit C, Smith P, Tuck G (2006) A coherent set of future land use change scenarios for Europe. Agriculture, Ecosystems and Environment 114: 57-68

Schneider SH (1997) Integrated assessment modelling of global climate change: transparent rationale tool for policy making or opaque screen hiding value-laden assumptions? Environmental Modelling and Assessment 2: 229-248 
Science and Policy Associates Inc and ESYS (1996) Proposal for a UK Integrated Climate Change Impacts Assessment. Report prepared for the Department of the Environment and the Environment Agency. Department of the Environment, London

Shackley S, Deanwood R (2002) Stakeholder perceptions of climate change impacts at the regional scale: Implications for the effectiveness of regional and local responses. Journal of Environmental Planning and Management 45(3): 381-402

Shackley S, Deanwood R (2003) Constructing social futures for climate-change impacts and response studies: building qualitative and quantitative scenarios with the participation of stakeholders. Climate Research 24(1): 71-90.

Strzepek K, Yates D, Yohe G, Tol RJS, Mader N (2001) Constructing "not-implausible" climate and economic scenarios for Egypt. Integrated Assessment 2: 139-157

Toth FL (2003) Climate policy in light of climate science: the ICLIPS project. Climatic Change 56: 7-36

Turner RK et al., (1998) Coastal management and environmental economics: analysing environmental and socio-economic change on the British coast. The Geographical Journal 164: 269-281

Turnpeny J, Haxeltine A, O'Riordan T (2004) A scoping study of user needs for Integrated Assessment of climate change in the UK context: Part 1 of the development of an Interactive Integrated Assessment Process. Integrated Assessment 4(4): 283-300

Turnpenny J, O'Riordan T, Haxeltine A, (2005) Developing regional and local scenarios for climate change mitigation and adaptation; Part 2: Scenario creation. Tyndall Working Paper 67, Tyndall Centre for Climate Change Research

Tyson P, Steffen W, Mitra AP, Fu C, Lebel L (2001) The earth system: regional - global linkages. Reg. Environ. Change 2: 128-140. 
UKCIP [United Kingdom Climate Impacts Programme] (2001) Socio-economic scenarios for climate change impact assessment: a guide to their use in the UK Climate Impacts Programme. UKCIP, Oxford

van Asselt MBA, Rijkens-Klomp N (2002) A look in the mirror: reflection on participation in integrated assessment from a methodological perspective. Global Environmental Change 12: 167-184

Wolfe AK, Kerchner N, Wilbanks T (2001) Public involvement on a regional scale. Environmental Impact Assessment Review 21: 431-448

Yarnal B (1998) Integrated regional assessment and climate change impacts in river basins. Climate Research 11(1): 65-74

Yohe G, Jacobsen M, Gapotchenko T (1999) Spanning "not implausible" futures to assess relative vulnerability to climate change and climate variability. Global Environmental Change 9: 233-249 
Table 1 Characteristics of the study regions

\begin{tabular}{|c|c|c|}
\hline & \multicolumn{2}{|c|}{ Region } \\
\hline & North West England & East Anglia \\
\hline Size and population & $14,000 \mathrm{~km}^{2} ; 6.8$ million & $12,500 \mathrm{~km}^{2} ; 2.2$ million \\
\hline Development & $\begin{array}{l}\text { Extensive urban development } \\
\text { within } \\
\text { Manchester/Merseyside } \\
\text { conurbations }\end{array}$ & $\begin{array}{l}\text { Low level of urbanization, } \\
\text { with the exception of large } \\
\text { urban centres such as } \\
\text { Cambridge and Norwich }\end{array}$ \\
\hline Flooding & $\begin{array}{l}\text { Flood-prone areas in narrow } \\
\text { river valleys and coastal fringes }\end{array}$ & $\begin{array}{l}\text { Significant low lying or } \\
\text { below sea level areas (e.g. } \\
\text { Fens and Norfolk Broads) } \\
\text { prone to coastal flooding }\end{array}$ \\
\hline Agriculture & $\begin{array}{l}\text { Mostly livestock farming } \\
\text { systems, extensive in uplands } \\
\text { and hills, but more intensive in } \\
\text { lowlands }\end{array}$ & $\begin{array}{l}\text { Intensively cultivated, with } \\
\text { an emphasis on arable } \\
\text { agriculture. } \\
\text { important. }\end{array}$ \\
\hline Water resources & $\begin{array}{l}\text { Mostly provided from surface } \\
\text { water resources, with significant } \\
\text { imports }\end{array}$ & $\begin{array}{l}\text { Greater dependence on } \\
\text { groundwater resources }\end{array}$ \\
\hline Biodiversity & $\begin{array}{l}\text { Important upland habitats (e.g. } \\
\text { upland hay meadows, artic } \\
\text { alpines) }\end{array}$ & $\begin{array}{l}\text { Important lowland (arable } \\
\text { field margins, fens) and } \\
\text { coastal (e.g. coastal grazing } \\
\text { marsh, saltmarsh) habitats }\end{array}$ \\
\hline
\end{tabular}


Table 2 Allowable scenario combinations within the Regional Impact Simulator

\begin{tabular}{l|ccccc}
\hline Timeslice/ & Baseline & Global & Global & Regional & Regional \\
Climate scenario & & Sustainability & Markets & Sustainability & Enterprise \\
\hline Baseline & $\checkmark$ & $\boldsymbol{x}$ & $\boldsymbol{x}$ & $\boldsymbol{x}$ & $\boldsymbol{x}$ \\
2020s Low & $\checkmark$ & $\checkmark$ & $\checkmark$ & $\checkmark$ & $\checkmark$ \\
2020s High & $\checkmark$ & $\checkmark$ & $\checkmark$ & $\checkmark$ & $\checkmark$ \\
2050s Low & $\checkmark$ & $\checkmark$ & $\checkmark$ & $\checkmark$ & $\checkmark$ \\
2050s High & $\checkmark$ & $\checkmark$ & $\checkmark$ & $\checkmark$ & $\checkmark$
\end{tabular}

$\checkmark$ Allowed $\quad \times$ Not allowed in the Regional Impact Simulator

Table 3 System performance of the Regional Impact Simulator

\begin{tabular}{|c|c|c|c|c|c|}
\hline PC 'type' & Processor & RAM & $\begin{array}{l}\text { Windows } \\
\text { Operating } \\
\text { System }\end{array}$ & $\begin{array}{l}\text { East Anglia* } \\
\text { runtime } \\
(\operatorname{secs})\end{array}$ & $\begin{array}{l}\text { North West* } \\
\text { runtime } \\
\text { (secs) }\end{array}$ \\
\hline $\begin{array}{l}\text { 'Old' (5 years } \\
\text { old) }\end{array}$ & $\begin{array}{l}\text { Pentium } 41.6 \\
\mathrm{GHz}\end{array}$ & $512 \mathrm{Mb}$ & 2000 & $29^{1}[54]^{2}$ & $36^{3}[65]^{2}$ \\
\hline $\begin{array}{l}\text { 'Typical' (3 } \\
\text { year old) }\end{array}$ & $\begin{array}{l}\text { Pentium } 42.8 \\
\mathrm{GHz}\end{array}$ & $1 \mathrm{~Gb}$ & $\mathrm{XP}$ & $14[28]$ & $19[31]$ \\
\hline $\begin{array}{l}\text { 'New' }(<1 \\
\text { year old }\end{array}$ & $\begin{array}{l}\text { Dual Core, } \\
3 \mathrm{GHz}\end{array}$ & $2 \mathrm{~Gb}$ & $\mathrm{XP}$ & $8[14]$ & 9 [19] \\
\hline \multicolumn{6}{|c|}{ * 2050s High climate + Regional Enterprise scenarios- all settings at default } \\
\hline \multicolumn{6}{|c|}{${ }^{1}$ Only saltmarsh habitat selected } \\
\hline${ }^{2}$ All habitats & elected & & & & \\
\hline
\end{tabular}




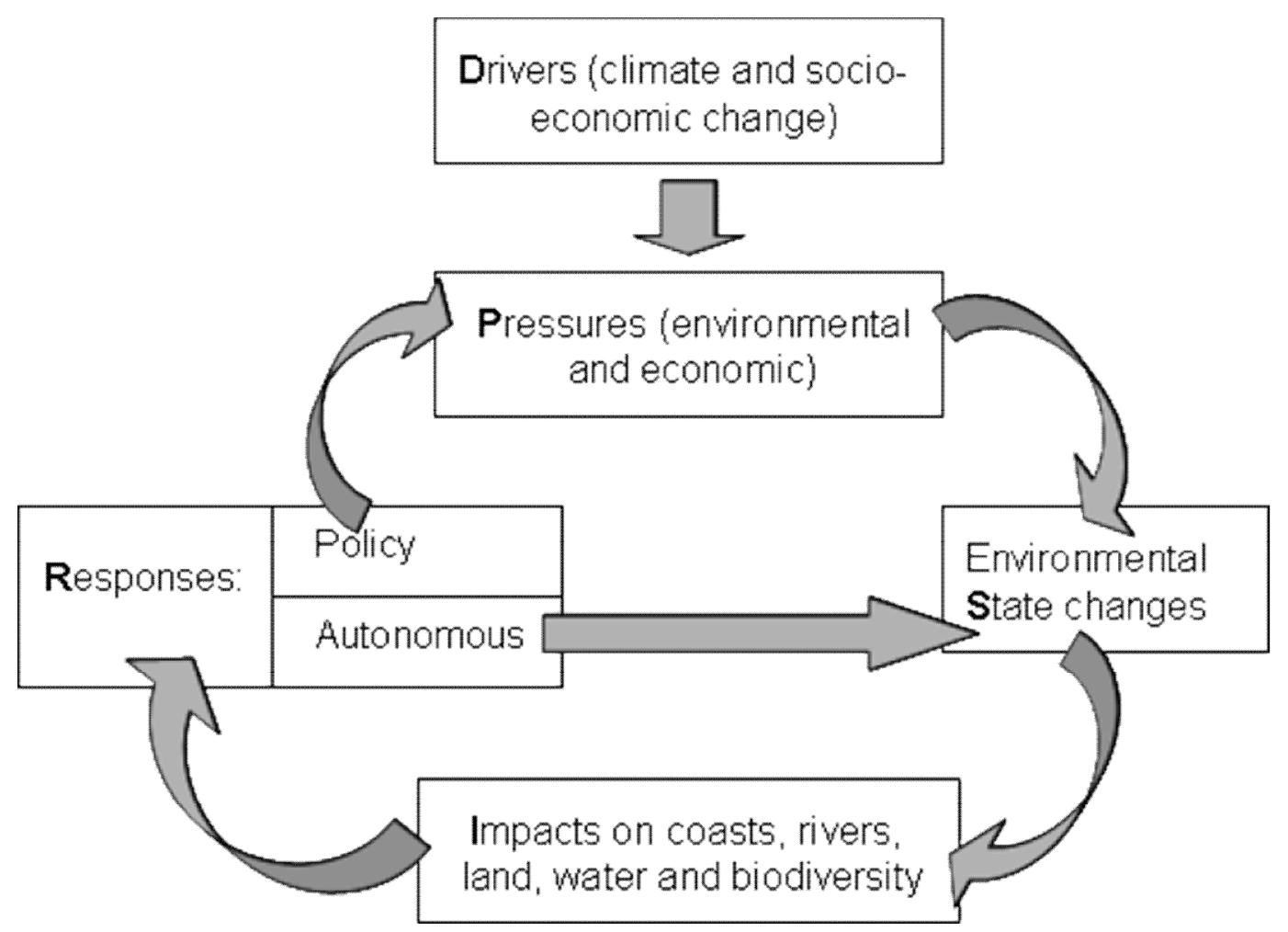

Figure 1 The 'Drivers-Pressure-State-Impact-Response' (DPSIR) framework applied in RegIS2 


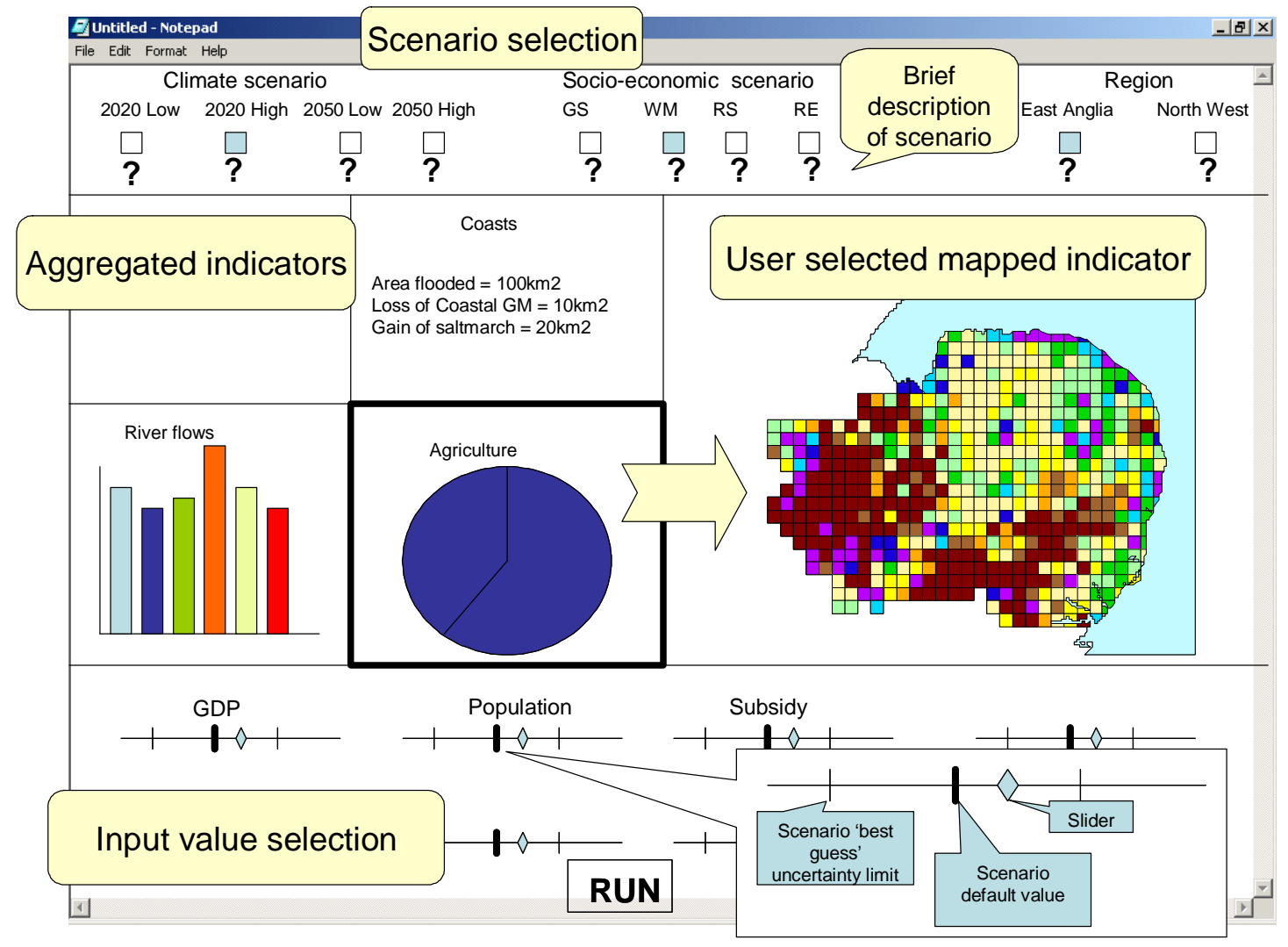

Figure 2 Initial design concept of the RegIS2 interface

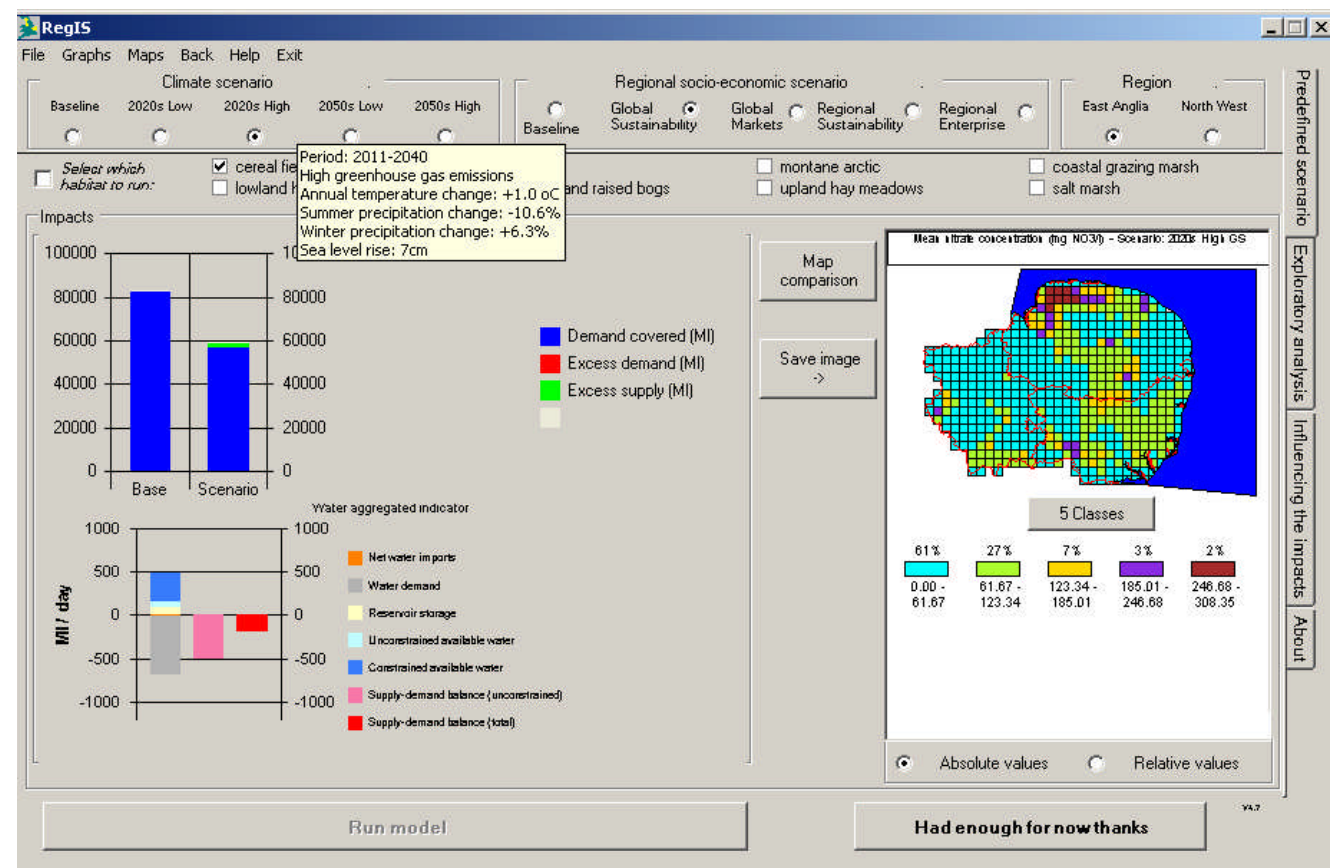

Figure 3 The 'Predefined Scenario Futures' screen, for investigating scenario combinations using default parameter values 


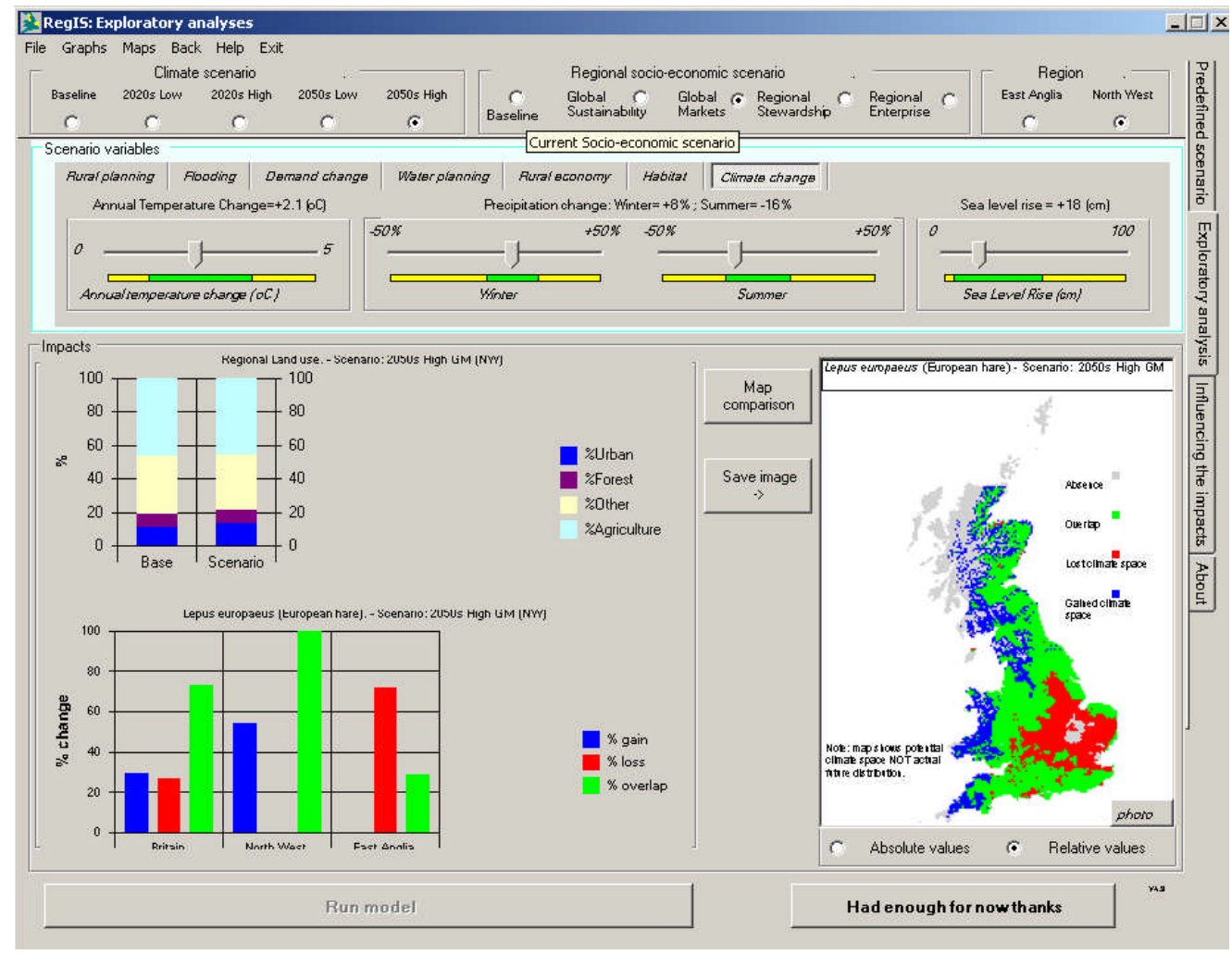

Figure 4 The 'Exploratory Analysis' screen for conducting sensitivity analysis and exploring scenario uncertainty and interactions 


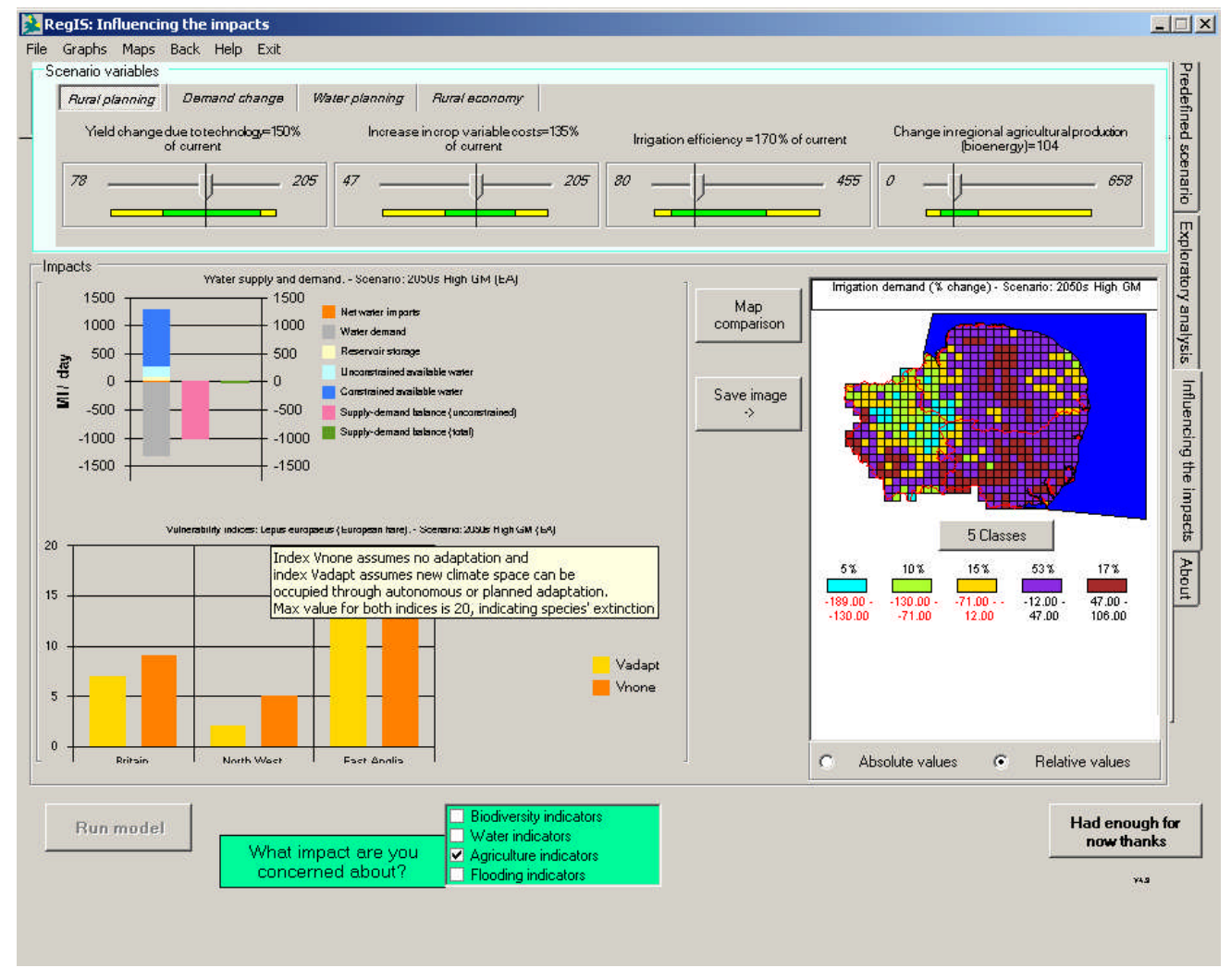

Figure 5 The 'Influencing the Impacts' screen for testing regional adaptation responses to identified impacts 


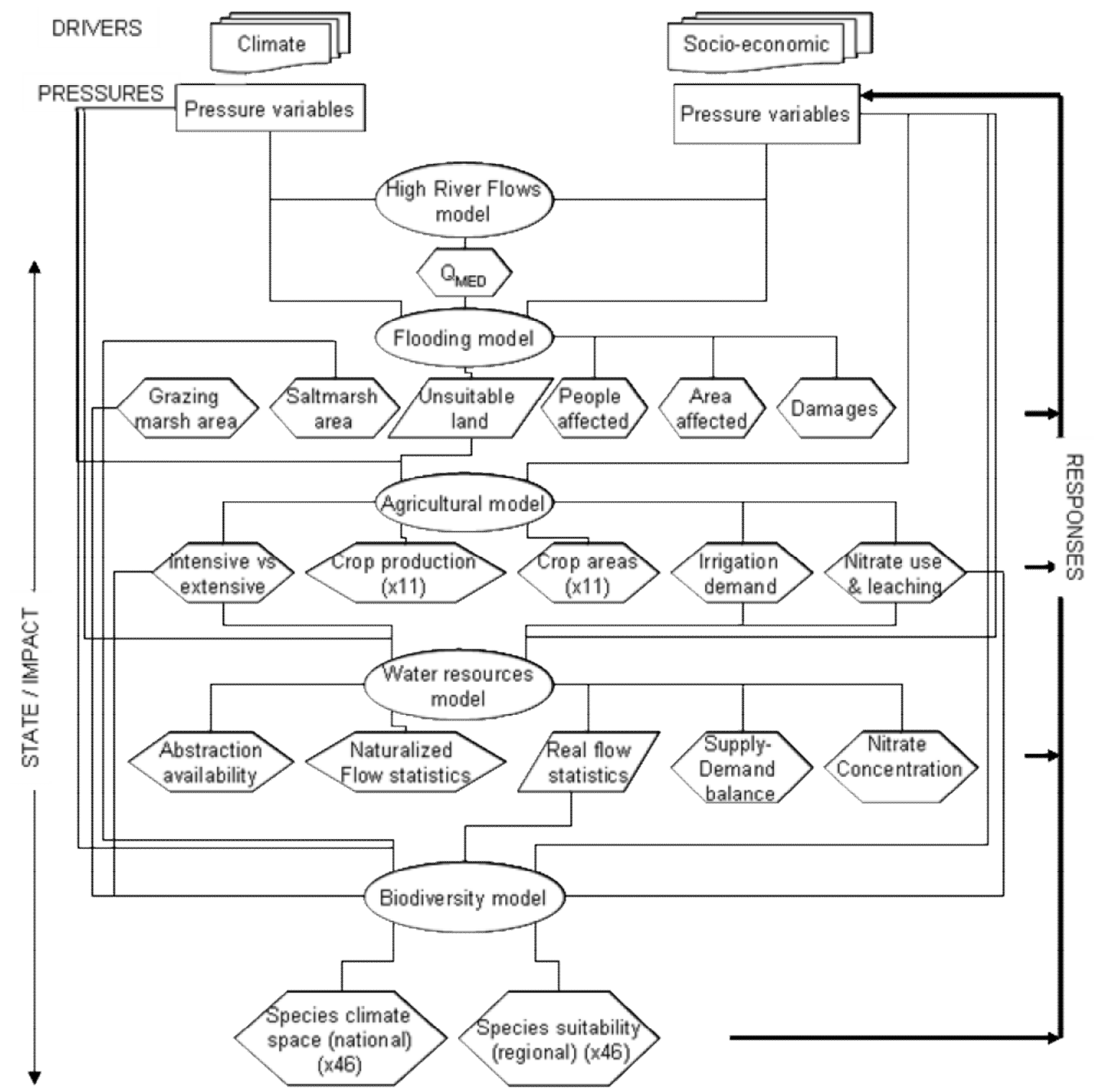

Figure 6 Schematic diagram of the model linkages within the DPSIR framework of the RegIS IAM [Hexagons are RegIS outputs; parallelograms are internal model outputs] 